\title{
Hauntology of Responsibility: Tom Stoppard's Darkside
}

\author{
Tymon Adamczewski \\ Kazimierz Wielki University in Bydgoszcz \\ tymon.adamczewski@ukw.edu.pl
}

Received 24 March 2017; accepted 5 October 2017.

\begin{abstract}
The article centres on the notion of responsibility in Tom Stoppard's Darkside (2013). While Pink Floyd's original album, which inspired the playwright, thematises its connection to ethics in a spectral and hauntological manner, through the use of field recording sound snippets interwoven in the music, the radio play explores the notion of responsibility through what is called "thought experiments." The article identifies the subversive function of these narrative examples and, following Emanuel Levinas' suggestions concerning the instability of the link between the philosophical discourse and that of examples, shows the latter's insolent and disruptive nature. The notion of responsibility is further linked to its discussion by Jacques Derrida in his Gift of Death (1995) which consequently makes it possible to view the relation between responsibility and responding from a subversive, hauntological and undecidable perspective.
\end{abstract}

Keywords: ethics; responsibility; Jacques Derrida; Tom Stoppard; music.

Darkside is a radio play by Tom Stoppard, the Czech-born British playwright, commissioned for BBC Radio 2. First broadcast on 26 August 2013 to celebrate the $40^{\text {th }}$ anniversary of Pink Floyd's Dark Side of the Moon, this radio comedy drama incorporates the music from the original record, Roger Waters' lyrics and Stoppard's own ideas in the form inspired by diverse aspects of the musical material. The record, often considered as a pinnacle achievement of the group, ranks among the most popular and instantly recognizable concept albums in contemporary popular culture. Its landmark position stems from various reasons, ranging from minimalistic yet iconic record sleeve, pioneering sound engineering (use of innovative recording techniques, like multi-track or loops), or the way music, typically for the group, is intertwined with snippets of field recording (voices, sound effects, etc.). In fact, it is the sounds, apart from the philosophical themes of time, ageing, critique of 
materialism, consumerism or madness of contemporary life expressed in the lyrics that seem to haunt the album and constitute a spectral trait of both the recording and the play.

While partly accounting for the album's unwaning popularity, the haunting traits are noticeable already at the structural level of the recording and in many cases contribute to the resistance to semantic closure. Recorded voices, laughter, sounds of heartbeat (which open and close the album) - all such effects trouble the listener and challenge the very perception of what otherwise might simply be popular music. While discussing similar yet immediately spectral sounds like the high-pitched violin or white noise, Isabella van Elferen (2012), in her book on Gothic Music and the uncanny, points out that effects like these suggest a certain ghostly presence, "even when this presence is invisible or intangible" (2012, p. 4). Such elements "undermine closure" in musical reception and produce the effect which van Elferen terms "the sense of uncanniness in sonic liminality"-leading to the claim that "Gothic music is always spectral" (2012, p. 4). This qualification can actually be extended onto Pink Floyd's work, however, with the reservation that, although their music is not gothic music, the use of the real-world sound snippets ("I never said I was afraid of dying") produces the effect of spectral presence. In other words, even though Pink Floyd's record, despite its popularity, is not an example of classic pop music, it is the idea of "openness," or "undermined closure" which accounts for the spectral aspects of their music. Interestingly, among such traits are links to the ethical category of responsibility and ethics in general which, both, (re)appear throughout the musical work and Stoppard's radio play, thereby inviting a hauntological reading.

Responsibility, indeed, also seems to be a hauntologically hazy phenomenon. Paul Ricoeur, for example, speaks about this notion not only as a fairly recent one, and "not really well established within the philosophical tradition," but also as one inviting "a kind of vagueness [which] invades the conceptual scene" (2000, p. 11). Part of this ambiguity comes from an understanding of responsibility as an obligation - to "fulfill certain duties, to assume certain burdens, to carry out certain commitments," but also from the very "polysemy of the verb "to respond" taken as an answer as well as a response to "a question, an appeal, an injunction" (2000, p. 12). If we then consider responsibility as a state of being accountable for some action or event, such understanding of the notion can easily be identified at various levels of both texts (the record and the play). Both of them - in more than simply formal sense - seem influenced by the spectral quality of an ethical obligation: both rely on aural signification which seems to thematize the notion of responsibility either as small-scale embedded narratives, dialogues, or lyrics and real-life noises, fading in and out of the soundscape in a spectral way. Ethical terms seem thus to underlie much of the material not only in its content but in some cases in the very way in which the musicians were working on the album. Famous are the stories how during the recording sessions Waters recruited the staff, the temporary occupants of the studio and roadies to answer a series of questions printed on flashcards. These were ranging from general questions about a favourite colour to more specific ones, for example about the last time they were violent. The recorded answers were later on included in the final album. One such instance has the following form: 
HuHuh! I was in the right!

Yes, absolutely in the right!

I certainly was in the right!

You was definitely in the right. That geezer was cruising for a bruising!

Yeah!

Why does anyone do anything?

I don't know, I was really drunk at the time!

I was just telling him, he couldn't get into number 2. He was asking why he wasn't coming up on freely, after I was yelling and screaming and telling him why he wasn't coming up on freely. It came as a heavy blow, but we sorted the matter out.

(Pink Floyd, "Money", from 5:57 approx.)

It is in response to the question about moral qualification of the speaker's actions (being in the right) that the notion of responsibility appears. Interestingly, it functions within an ethical perspective and seems to haunt the person while at the same time indicating a certain spectral quality of responsibility. The recurring presence of other similar recorded responses and sounds, often barely audible on the album, shows how the record seems to act out an "unfamiliarly familiar" presence which might be connected with the quality of contemporary life. According to Sheila Whiteley:

The words act like dialogue over the music, impressionistic yet making a point. As the album deals with stress, lunacy and death in contemporary society, so the disembodied vocal timbres create effective commentary: cynical asides and taped effects underline the inhuman quality still further by creating an abstract collage against which to project the emptiness of modern life; while the electronic treatment of instrumental and vocal sounds helps to reinforce the distancing of space as signified through pure tone, electronically synthesized. (Whiteley, 2005, p. 117)

In his lyrics, Waters thus thematises its perception in the tradition of modernist cultural pessimism as, among other things, a set of recurrent images (cf. Weinstein, 2002) which could, in turn, be construed as a reading of how people's decisions and their actions seem to come back to them.

The plot of Stoppard's Darkside is loosely based on the outwardly philosophical themes of Pink Floyd's album. It is a story of Emily McCoy, a student of philosophy and a patient in an institution resembling an insane asylum run by Dr Antrobus who is administering her treatment. The generally linear story is presented through a series of scenes, corresponding to the tracks on the album, and constitutes an exploration of ethical and moral dilemmas referred to as "thought experiments." These have the form resembling smallscale exemplary narratives illustrating some ethical problems, initially discussed in a philosophy course Emily is attending. The stories in question, however, are often problematised either by the main character's responses to them, or by the fact that the characters of these stories are brought to life and have to live through the consequences of the ethical 
dilemmas posed within such narratives. In the course of the play Emily interacts in various ways with such characters. In the opening scene, for example, we encounter Ethics Man who, after being introduced in the "American comic-book style," switches points and sacrifices the life of a boy in order to save more human lives on a runaway train (Stoppard, 2013 , p. 7). Afterwards, we return to philosophy class where Mr Baggott — soon to be revealed as the Ethics Man himself-asks about the superhero's moral philosophy. Curiously enough Emily has substantial doubts about the whole narrative and asks follow-up questions about the details of the characters of the story: Who was on the train? Who was the boy who got hit by the train? (Stoppard, 2013, p. 9). This seems to dislodge the moral dilemmas from their usual functions within ethics as a discourse. Moreover, such narrative techniques which introduce an ethical problem only to propose a non-standard resolution (e.g. the use of common land example; Stoppard, 2013, pp. 24-25) not only establish an ironic angle to the story but also point to the fact that ethics seems to be at its vital centre.

Nevertheless, as it is visible from its very beginning, the play's understanding of ethics runs against the traditional definition of this philosophical discourse, where "ethics is the arena in which the claims of otherness - the moral law, the human other, cultural norms, the Good-in-itself - are articulated and negotiated" (Harpham, 1995, p. 394). In the play, ethics as a philosophical discourse on morality is reflected as a paradox. Emily is introduced as a philosophy student trying to learn about "moral actions, the just society . . . Plato, Rousseau, Immanuel Kant who questions the legitimacy or the very point of examples used as moral dilemmas" (Stoppard, 2013, p. 12). When she meets a Boy from one of the thought experiments her doubts about ever obtaining an answer or reaching some transcendental point of certainty become sealed. While speaking about the juggler on the radio (such transcendental presence), he confirms the helplessness of "philosopher-type people" who actually fail at providing any material attempts at clarifying the difference between "a juggler you can't see, hear, smell or touch" and no juggler at all; according to the Boy, "there's nothing any of these people can tell each other about the existence or the non-existence of the juggler" (Stoppard, 2013, p. 13). Such remarks seem to evoke the nature of the discipline which promises answers but instead is only obsessed with questions - like for example "how ought one live?" or "what ought one do?" (Harpham, 1995, p. 395). In other words, instead of providing solutions traditionally understood ethics turns out to rest on "articulating perplexity, rather than guiding" (Harpham, 1995, p. 395). Stoppard's Darkside reflects such paradoxical status of ethics through the thought experiments which constitute embedded narratives about moral choices. Their role, however, is certainly deconstructive as they act out the consequences of the example-stories only to dislodge the ethical discourse from its explanatory position.

In this respect, Stoppard's play may be taken as an attempt to get to grips with the philosophy's impact on human life, as it seems to have identified the problematic status of examples within ethical theory. On the one hand, as Geoffrey Harpham aptly points out, in such a discourse a "narrative serves as the necessary 'example,' with all the possibilities of servility, deflection, deformation, and insubordination that role implies" (1995, p. 401); on the other, moral philosophers, as the play also emphasises, are not exactly keen on 
advising on the properly moral course of action. Instead, what they focus on is just telling more stories. This, in turn, may stem from the very nature of an example; or even further, from the polyvalence of stories and language, because the example may be seen as introducing "an element of risk into the fabric of assertive discourse" (Davis, 2004, p. 88).

Such tradition of reluctance and reservation towards examples (often in the narrative form) can be evidenced with the work of philosophers representing disparate traditions of understanding ethics. One such case, concerning telling lies and an obligation to tell the truth, comes from Immanuel Kant. While illustrating how, despite being a violation of the categorical imperative, in some situations one has to tell a (benevolent) lie in order to save others (e.g. the story of a murderer inquiring about the whereabouts of a friend hiding in our house), the philosopher expresses his reluctance towards such exemplary stories or narratives (cf. Davis, 2004, pp. 87-89 et passim). Interestingly, a similar reluctance towards the use of narratives as examples can be found in the works of a philosopher representing a somewhat different approach to ethics and responsibility, namely Emmanuel Levinas. In the case of his works, the trouble with examples, and more widely with literature, stems from seeing narratives as embodying what might be termed as the structure of exemplarity. This may roughly indicate literature's ability to serve as an example of a world and the behaviour of its inhabitants (including their decisions). One should not find this particularly surprising, if for Jonathan Culler, for instance, this trait of literature may be seen as paradoxical in its own right:

The special structure of exemplarity at work in literature allows for the ease with which readers and critics come to speak about the "universality" of literature. Hamlet, for instance, presents itself as in some way exemplary ..., but it simultaneously declines to define the range or scope of that exemplarity. Hence the ease with which readers and critics come to speak about the "universality" of literature. The structure of literary works is such that it is easier to take them as telling us about "the human condition" in general than to specify what narrower categories they describe or illuminate. (Culler, 2000, p. 36)

Despite literature's propensity for activating universal features of literature (such as universal readings resulting, for example, in national canons), it is precisely this universal potential of exemplarity inherent in literature - in a way close to the poststructural semantic polyvalence of texts - that accounts, at least partly, for the problems ethical discourse has with narrative examples. The vexed nature of this relationship is visible in the sparse use of such exemplary stories in as disparate strands of ethics as the ones exemplified by Kant or Levinas. As Davis observes, Kant's reluctance to use examples stems from the risk that "they may reveal a weakness within his ethics; in Levinas' writing, on the other hand, weakness is disclosed by the absence of examples, related to a more general suspicion of narrative literature" (Davis, 2004, p. 101). What is interesting is that in both cases stories, narratives (and literature in general) connote a certain threat or something potentially dangerous to the coherence and integrity of what the philosophers are discussing.

Despite the overall reluctance towards examples and their effectivity, they may be seen as performing a "double function." In Levinas' readings of Talmud he states that 
notions remain constantly in communication with examples, or they return to them, even though they ought to have been happy to serve as springboards to reach generality, or else they illuminate thought which probes by the secret light from hidden or isolated worlds in which it irrupts. (Levinas, 1982, p. 127)

As Davis (2004, p. 95) identifies, not only examples never are "mere illustrations, since they are dynamically involved in the unending process of meaning . ..," but they may be indicative of an incessant and unstoppable economy of exchange which, in Levinas' understanding of links between the notion and the example, however, neither "occupies a stable position as illustration or truth of the other. The example is insolent and disruptive in regard to the authority of the notion." One solution Levinas proposes to such untamed status of examples is performative - in other words, to attempt a "different" type of writing, one which can be qualified as an "ethical performance" (like Otherwise than Being for Davis, 2004, p. 99); or as one which performs what the discourse discusses (cf. Critchley, 1999; Eaglestone, 1997).

The insolent and disruptive performance of the example in the form of a story or an ethical dilemma, as visible in Stoppard's Darkside, amounts to quite a few thought experiments. All these tiny narratives discuss the notion of responsibility - e.g. the death of many against the death of one; deciding whose life to save first, or the destruction of ecosystem through irresponsible and unsustainable farming practices. In the same way, they perform an unruly task towards the purpose of illustrating the seemingly insoluble and universal nature of an ethical problem because they are saturated with context, meaning and actual characters with whom Emily interacts. As an alternative to taking the stories at their face value, as it were, Emily probes the consequences of a given narrative and reveals their singularity. This leads her to recognise the abstract, detached-from-life status of the problems she is to solve:

Mr Baggot, you're supposed to be cleverer than me because you're the teacher but your games and thought experiments are stupid. In proper life people aren't just out for themselves and there's always a million things you don't know, but your stick-figures think they can work out the answers like doing a Sudoku. And what I'm thinking is, you can't work out what is the good, you just know what is the good, that's what's good about it. (Stoppard, 2013, p. 32)

While refusing to treat the example-stories as brainteasers she opts for an intuitive understanding of ethical categories; she simply responds to the characters - similarly to the way in which the Pink Floyd's roadies were responding to Roger Waters' recording session questions. What these responses have in common is their relationship with the notion of responsibility, which, as Jacques Derrida shows, involves a connection with responding to the other, for example. What is more, for the philosopher, responding is precisely connected to "answering to the other, before the other and before the law, and if possible publicly, and answering for itself, its intentions, its aims, and for the name of the agent deemed responsible" (Derrida, 1996, p. 26). In his analyses this relationship, or the "relation between responsibility and responding is not common to all languages but it does exist in Czech (odpovědniost)" (Derrida, 1996, p. 27). Interestingly, this allows for a discussion from a hauntological and undecidable perspective: 
The concept of responsibility is one of those strange concepts that give food for thought without giving themselves to thematization. It presents itself neither as a theme nor as a thesis, it gives without being seen, without presenting itself in person by means of a "fact of being seen" that can be phenomenologically intuited ... More serious still, it must always run the risk of conversion and apostasy: there is no responsibility without a dissident and inventive rupture with respect to tradition, authority, orthodoxy, rule, or doctrine. (Derrida, 1995, p. 27; my emphasis)

Responsibility is thus, in a way, subversive and entails transgression of tradition or authority. In The Gift of Death Derrida also uses an example from the biblical story of Abraham's sacrifice to illustrate the paradox of the notion in question. However, for Derrida, responsibility is about a clash between a certain notion of ethics or universality and what might be termed as "radical singularity" of "Abraham's hyper-ethical sacrifice" (1995, p. 71). The notion is considered in processual terms as a wavering between the demands of this singularity, or "wholly other form of alterity" and more general demands of more general other(s). To put it differently, a response, or responsibility, towards "any one (that is to say to any other)" is always simultaneously also "failing in my responsibilities to all others, to the ethical or political generality" (Derrida, 1995, p. 70). The paradox of responsible behaviour thus presents responsibility as an undecidable, or an aporia, which the traditionally minded "knights of good conscience" gloss over, especially if they insist upon and preach a "sense of ethical or political responsibility" (Derrida, 1995, p. 67). Instead of our singular given moment of obligation, as the philosopher points out, "[t]here are also other others, an infinite number of them, the innumerable generality of others and universal responsibility (what Kierkegaard calls the ethical order). I cannot respond to the call, the request, the obligation, or even the love of another without sacrificing the other other, the other others" (Derrida, 1995, p. 68).

In The Gift of Death, Derrida demonstrates that such aporetic understanding of responsibility is, in fact, its "most most common and everyday experience" (1995, p. 67). The radical singularity of Abraham's responsibility towards God is at the same time a moment of "sacrificing ethics," or "sacrificing what ever obliges me to also respond, in the same way, in the same instant, to all the others" (Derrida, 1995, p. 68). The human condition is thus one where ethics is a continual sacrifice; a continuous moment of decision-making between our loved ones and our professional duties or individual and general responsibilities. Derrida's understanding of responsibility towards the other thus entails an irresponsibility towards other others (cf. Anderson, 2015). However, the necessity of such continuous choice-making leaves "a remainder," a trace of the moment of undecidability which responsibility brings, which haunts our existence.

It may well be that this haunting remainder is related to the aspect which is frequently overlooked in the ethical and moral dilemmas, namely emotions. When the thought experiments are considered only in their logical dimension they simply constitute a dry exercise in reasoning, but, as Stoppard's work evidences, the emotional perspective should also be taken into consideration, even though it might "lead to widespread unemployment among moral philosophers" (Stoppard, 2013, p. 32). In other words, the play seems to 
illustrate that more important and fruitful than asking (distressing) questions such as "What is the Good?" are questions about the singularity of a given situation: the ones posed by Emily as content questions (Who was the boy who got hit by the train?) which include her meditations on the context of the narratives: "[a]nd how about them on the train? Who's to say he didn't save a serial killer? Or a mad bomber on a date with destiny?" (Stoppard, 2013, pp. 49, 9, 11). These serve to expose the abstract and, in a way, inhumane nature of the ethical exemplary narratives. Derrida makes a reference to a similar perspective when he qualifies Abraham's story as infanticide: "[ $\mathrm{t}]$ he story is no doubt monstrous, outrageous, barely conceivable: a father is ready to put to death his beloved son, his irreplaceable loved one, and that because the Other, the great Other asks him or orders him without giving the slightest explanation"; the terms used are certainly ones of emotional impact - "what could be more abominable, what mystery, could be more frightful (tremendum) vis-a-vis love, humanity, the family, or morality?" (1995, p. 67). Stoppard's Darkside seems to side with the emotional perspective on ethical and moral choices, since the main character not only interacts with the characters of the thought experiments, but in the play's narrative resolution both Emily and the (dead) Boy, who accompanies her through most of the story, are rescued by the people from the train Ethics Man had saved at the play's beginning.

Such (emotional) understanding of responsibility is not only visible in the play or Pink Floyd's record, but can partly account for the album's popularity, perhaps also indicating the reasons why Stoppard decided to rework and develop themes present already in the musical text. The positive response to the record falls onto a time identified by Eva Illouz in her Cold Intimacies (2007) as the period when the economic and the emotional domains of human life overlap. As she observes, modern individualism has not only become emotional but even dominated by economy. In turn, the economic and the political models of exchange have become models for emotional relationships, infiltrating the relationships between people, even the intimate ones. According to Illouz, while the social consequences of contemporary preoccupation with emotions testify to the mutual link between the economic and the emotional spheres, responsibility becomes linked to identifying one's position, or to

the relationship of the self to culturally situated others. When you tell me "you are late again," whether I feel shame, anger, or guilt will depend almost exclusively on my relationship to you. My boss's remark about my being late is likely to shame me, a colleague's is likely to make me angry, but if it is my child waiting for me at school, it is likely to make me feel guilty. (Illouz, 2007, p. 3)

This feeling of guilt or responsibility has become a significant element contributing to the construction of one's identity in the contemporary world. Part of this stems from the fact, recognised by Derrida, which makes us see (moral) choices as undecidable transgressions against our responsibilities to others. As we have seen in the case of Pink Floyd's Dark Side of the Moon, the pervasive feeling of guilt may take on a haunting form-indicating the spectral nature of the notion of responsibility. This, on the one hand, may be seen as the 
reason for the band's success and, on the other, as an illustration of the fact that audiences could perhaps, at some level, relate to the more individualistically driven times of the early 1970s (cf. Whiteley, 2005) but also to such recurrent understanding of responsibility.

In this respect Pink Floyd's record, reworked by Stoppard forty years later, testifies not only to the unfading popularity of the haunting music and lyrics, but also to the very haunting nature of moral choices in contemporary world. My initial aim was to look at the two texts from a hauntological perspective at the way they discuss the notion of responsibility. While the original musical material, through the use of real life recorded snippets, often thematises the negative outlook on society within ethical terms, Stoppard's play explores the notions of moral dilemmas and examples within the ethical critical discourse. In fact, following the vexed nature of the notion of responsibility — read as a certain ethical obligation-Darkside speaks about the deconstructive consequences of using example-stories which reveal the paradoxical status of ethics. Putting responsibility, as Derrida does, in the context of a subversive aporia, may lead to viewing it as an undecidable which is transgressive towards authority or tradition of an explanatory discourse. Through their structure of exemplarity, however, examples - and literature in general - can connote a threat to the integrity of philosophical discourses. The individualism of contemporary life, together with the decision making process it involves, produces ethical spectres which haunt people and force them to reconsider the responsibility for their actions. Such obligation, as Stoppard's play encourages us to see it, may become problematic due to its entanglement in the domain of the affect, usually neglected by the dry and academic ethical discourse.

\section{References}

Anderson, N. (2015). Deconstruction and ethics: An (ir)responsibility. In C. Colebrook (Ed.), Jacques Derrida: Key concepts (pp. 48-57). London, UK: Routledge.

Critchley, S. (1999). The ethics of deconstruction: Derrida and Levinas ( $2^{\text {nd }}$ ed.). Edinburgh, UK: Edinburgh University Press.

Culler, J. (2000). Literary theory: A very short introduction. Oxford, UK: Oxford University Press.

Davis, C. (2004). After poststructuralism: Reading, stories and theory. London, UK: Routledge.

Derrida, J. (1995). The gift of death. (D. Willis, Trans.). Chicago, IL: The University of Chicago Press.

Eaglestone, R. (1997). Ethical criticism: Reading after Levinas. Edinburgh, UK: Edinburgh University Press.

van Elferen, I. (2012). Gothic music: The sounds of the uncanny. Cardiff, UK: University of Wales Press.

Harpham, G. G. (1994). Ethics. In F. Lentricchia \& T. McLaughlin (Eds.), Critical terms for literary study ( $2^{\text {nd }}$ ed.) (pp. 387-405). Chicago, IL: University of Chicago Press.

Illouz, E. (2007). Cold intimacies: The making of emotional capitalism. Cambridge, UK: Polity Press. 
Levinas, E. (1982). L'Au-delà du verset: Lectures et discours talmudiques. Paris, France: Minuit.

Pink Floyd. (2011). Dark Side of the Moon [CD]. USA: Capitol Records. (Original record 1973)

Ricoeur, P. (2000). The concept of responsibility: An essay in semantic analysis. In P. Ricoeur, The just (pp. 11-35). (D. Pellauer, Trans.). Chicago, IL: University of Chicago Press.

Stoppard, T. (2013). Darkside. London, UK: Faber and Faber.

Weinstein, D. (2002). Progressive rock as text: The lyrics of Roger Waters. In K. Holm-Hudson (Ed.), Progressive rock reconsidered (pp. 91-110). London, UK: Routledge.

Whiteley, S. (2005). Pink Floyd: Dark Side of the Moon. In S. Whiteley, The space between the notes: Rock and the counter-culture (pp. 103-118). London, UK: Routledge. 